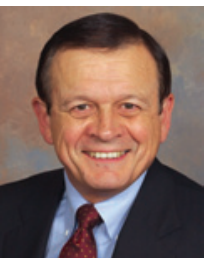

Scientific society leaders often express concern about the difficulty of encouraging young professionals to regularly contribute to conferences, publications, and society activities. While it is true that these young people have many pressures placed upon them, it is also true that active participation in the scientific enterprise is useful for career advancement.

Several ideas have been offered to encourage young researchers to participate. Some societies have made a conference rule that each symposium must be co-chaired by a young person who shows promise. Some societies have a committee for young people so that there is a home for them in the society. The "meal with a mentor" concept is another idea. At the annual M\&M conference, meeting awards are presented to students and post-doctoral researchers to defray the expense of meeting attendance; unfortunately, we do not keep track of which awardees continue to participate in the society.

How do we identify early career people who can step up to chair symposia and take leadership positions in their particular discipline? Perhaps a different question should be asked: Where are the mentors who could encourage these young investigators and recommend them for leadership positions?

Often a mentor is a colleague who knows the young person at his or her place of employment. A mentor also can be someone who hears an excellent talk and does more than just applaud; he or she makes a point of meeting the speaker and discussing the person's research. Perhaps the mentor participates in a spirited discussion at the young person's poster. While these interactions may be memorable and helpful, it may be more beneficial for the mentor to put in a good word with the symposium chair or the next program chair. I believe it is especially important to encourage women in this way.

Mentoring can also be important for mid-career professionals. This is a point in a career when opportunities arise for volunteering outside one's employment, and a mentor can be helpful in deciding how to find time to give back to the community without losing track of one's career advancement. Of course, mid-career is when a professional should begin to develop one's own mentoring skills.

Personally, mentors were quite important to my career. I can identify at least two senior researchers who recommended me for important career-enhancing positions. Of course, that was only half the bargain; I had to complete those tasks with competence and enthusiasm for my career to be positively affected.

Here is my point. It would be wonderful if more senior investigators would serve as mentors for the young people they encounter, but perhaps this natural mechanism does not work as well as it should. What can societies do to encourage mentorship?

Charles Lyman

Editor-in-Chief

Publication Objective: to provide information of interest to microscopists.

Microscopy Today is a controlled-circulation trade magazine owned by the Microscopy Society of America that is published six times a year in the odd months. Editorial coverage spans all microscopy techniques including light microscopy, scanning probe microscopy, electron microscopy, ion-beam techniques, and the wide range of microanalytical methods. Readers and authors come from both the life sciences and the physical sciences. The typical length of an article is about 2,000 words plus figures and tables; feature articles are longer. Interested authors should consult "Instructions for Contributors" on the Microscopy Today website: www.microscopy-today.com.

\section{ISSN 1551-9295}

\section{Disclaimer}

The Microscopy Society of America and the editors cannot be held responsible for opinions, errors, or for any consequences arising from the use of information contained in Microscopy Today. The appearance of advertising in Microscopy Today does not constitute an endorsement or approval by the Microscopy Society of America of any claims or information found in the advertisements. By submitting a manuscript to Microscopy Today, the author warrants that the article is original or that the author has written permission to use copyrighted material published elsewhere. While the contents of this magazine are believed to be accurate at press time, neither the Microscopy Society of America, the editors, nor the authors can accept legal responsibility for errors or omissions.

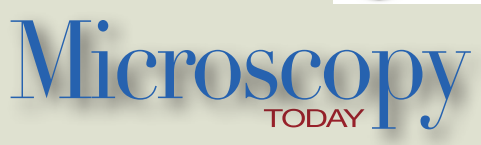

Editorial Staff

Charles E. Lyman, Editor-in-Chief

charles.lyman@lehigh.edu

(610) 758-4249

Gennifer Levey, Production Manager glevey@meridianartpro.com (212) 780-0315

Ron Anderson, Executive Editor microscopytoday@tampabay.rr.com

Phil Oshel, Technical Editor

oshellpe@cmich.edu

Stephen Carmichael, Columnist carmichael.stephen@mayo.edu

Michael Davidson, Pioneers Editor

davidson@magnet.fsu.edu

Steven Barlow, Education Editor sbarlow@mail.sdsu.edu

Thomas E. Phillips, Consulting Editor phillipst@missouri.edu

E. Ann Ellis, Microscopy 101 Editor eann.ellis@suddenlink.net

Paul Webster, Calendar Editor

pwebster@usc.edu

John Shields, Humor Editor

jpshield@uga.edu

Nikolaus Cordes, Digital Content Editor ncordes@lanl.gov

Thomas Kelly, Chief Awards Judge

Thomas.kelly@ametek.com

Advertising Sales

M.J. Mrvica Associates, Inc.

2 West Taunton Avenue, Berlin, NJ 08009 mjmrvica@mrvica.com

(856) 768-9360

Kelly Miller, Account Manager

kmiller@mrvica.com

Magazine website:

http://www.microscopy-today.com

Free subscriptions are available

Publisher

Cambridge University Press

32 Avenue of the Americas

New York, NY 10013-2473

(212) 337-5000

Circulation: 18,000

Editorial Board

Arlan Benscoter, Lehigh University

John Bozzola, Southern Illinois University

Peter Crozier, Arizona State University

Vinayak Dravid, Northwestern University

David Grubb, Cornell University

Bryan Huey, University of Connecticut

John Mackenzie, North Carolina State Univ.

Paul Maddox, University of Montreal

Ania Majewska, U. Rochester Med School

Greg Meeker, U.S. Geological Survey

Joseph Michael, Sandia National Labs

Caroline Miller, Indiana University

Brian M. Patterson, Los Alamos National Lab

Robert Price, University of South Carolina

John Reffner, John Jay College, SUNY

Ian Robertson, University of Wisconsin

Phillip Russell, Appalachian State University

Glenn Shipley, Citizen Microscopist

Robert Simmons, Georgia State University

Paul Voyles, University of Wisconsin

Simon Watkins, University of Pittsburgh

Cynthia Zeissler, Nat. Inst. of Sci. and Tech. (NIST) 